MANAGEMENT ISSUES IN
HEALTHCARE SYSTEM
WwW.AIMIJOURNAL.COM

\title{
Study of the relationship between information technology and knowledge management in the headquarters of Tehran Social Security Organization
}

\author{
Attieh S.Mirakbari ${ }^{1 *}$, Sedigheh Abedini ${ }^{2}$, Hesamaddin Kamalzadeh ${ }^{3}$ \\ ${ }^{1}$ Masters student, Management department, Bandar Abbas Branch, Islamic Azad University, Bandar Abbas, \\ Iran \\ ${ }^{2}$ Assistant Professor of Health Education. Social Determinants in Health Promotion Research Center, \\ Hormozgan University of Medical Sciences, Bandar Abbas, Iran \\ ${ }^{3}$ Assistant Professor of Information System. Department of Community Medicine, Health Information \\ Management Research Center, Hormozgan University of Medical Sciences, Bandar Abbas, Iran
}

Keywords:

information technology, knowledge management, social security organization

Correspondence: ea.mirakbari@gmail.com

\section{Abstract}

Information technology and knowledge management are two important matters in the modern organizations of this era. The biggest factor in the success of knowledge management in the present era is the potential that information technology creates for it. Therefore, the purpose of this paper is to determine the relationship between information technology and knowledge management in the headquarters of the Social Security Organization. The research method was descriptive-correlational and the statistical population was 620 Experts and senior staff of headquarters of the social security organization. Of these, 237 were selected by random sampling method based on Cochran's formula. Collected information through questionnaire were analyzed using SPSS and LISREL softwares. The results indicated a significant relationship between information technology and knowledge management in the headquarters of the Social Security Organization as well as the relationship between information technology and knowledge management components such as (acquisition, creation, storage, distribution, maintenance). According to the Friedman test, knowledge storage was highly related to information technology in the organization under study. 


\section{Introduction}

In the present era, the use of information technology as one of the most well-known technological effects in organizations has become necessary due to public expectations of citizens, and promoting organizational efficiency, reducing administrative costs, clarifying, providing people with satisfaction, providing good services for citizens, and speeding up service provision (Esfandiari Moghadam \& Safarzadeh, 2012; Fani \& Mosleh, 2007). On the other hand, today knowledge plays an important role in the economy of the countries (Rabiei \& Maali, 2012) and organizations need to implement knowledge management to succeed in the economy knowledge (Wilcox, 1997).

It is believed that the greatest factor in the success of knowledge management in the present era is the potential that information technology creates for it (Wang, Klein, \& Jiang, 2007). Although some authors believe that information technology is a component of knowledge management and does not have the ability to increase organizational knowledge (Koskinen \& Pihlanto, 2008). Some also insist that information technology ignores implicit knowledge and only deals with the aspect of explicit knowledge encoding (Sherif \& Xing, 2006). Some also believe that the use of information technology increases employees' knowledge and awareness as well as the enrichment of job content. Furthermore, knowledge of the employees leads to their professional hegemony on the organization (Sarafizadeh, 2009).

The Social Security organization is a social insurance organization that covers wage and salary of workers (Forced) and self-employed (optional). It covers more than 39 million people along with their families. Therefore, considering the huge range of customers and the breadth and complexity of its structure, this organization is committed to utilizing the latest scientific achievements and new technologies through the dynamic and effective presence in business environments as well as committed to transparency and responsiveness and timely fulfillment of legal obligations to customers and to protect resources and enhance the value of its reserves. In this regard, the use of information technology and knowledge management in the social security organization has led to an increase in the level of staffing, efficiency and solving the problems of major organizations in the era of modern change and promotion. Following transparency and accuracy and speed of responsiveness have increased. Therefore, this research seeks to study the relationship between information technology and knowledge management in the headquarters of the Tehran Social Security Organization.

\section{Theoretical Framework of research \\ Information technology}

NSIT introduces information technology that includes communication technologies, a number of robust computers, and software that can be considered as the point of convergence of electronics, data processing and long distance communication and describes the need for it by mentioning three factors, first, profitability of the information technology industry as the strategic industrial in the world; second, information technology is a key technology and applies to all industries and services; third, information technology is a fundamental infrastructure that reduces costs and finally leads to increased efficiency and product quality and also allows all institutions and economic units to share knowledge and transfer (Mohamadi, 2005).

Information technology includes a wide range of inventions and communication media 
which connects information systems and individuals to each other. Systems that are often interconnected and usually use them together in the name of information technology. Systems such as voice mail, e-mail, audio conferencing, video conferencing, Internet, groupware and shared Internet, special telephones, fax machines, digital personal assistants, and more (Dewitt \& Jones, 2001).

\section{Theories of Technology}

\section{Zeleny's theory of technology}

Technology is the use of regular and systematic knowledge to produce a product, creates a process, or provides a service with components, hardware, software, brainware, communication network and support. Production technology without Information technology can never be possible. Change in technology means change in all dimensions, because technology integrates the expansion of the system, knowledge and work together; therefore, technology even changes the philosophy of work and culture.

\section{Skinner's theory of technology}

Major changes in management are due to the developments of technology. New technology creates new threats and opportunities, and changes in technology change the way businesses operate and transform organizational and social systems, promotes efficiency and economic development, and adds to living standards and enhances competitive advantage.

\section{Adsmoan's theory of technology}

According to Adsmoan, technology management is an interconnected process that involves both manager and staff with the ultimate goal of innovation, design, product development, and improved working conditions.

\section{Somans's theory of technology}

According to Somans, technology is not definitive, but a continuous process in five steps: Knowledge about technology, gaining technology, adaptation and compliance with the requirements of the organization, evolution of technology, and technology decline (Kamrani, 2007).

\section{Advantages of Information Technology}

At the beginning of the 21st century, the use of information technology to facilitate communication and coordination in the research and application of information systems became an important issue. Most of these uses are categorized into two categories: Operational application, the use of information technology in a specialty is called the operational application of information technology such as list of employee salaries, production and distribution planning, and etc. At this level, the computer as a device and mechanical tool of converting inputs to outputs expands the automation of office work and ultimately leads to cost savings and speeds up works.

Information application, information application of Information technology use facilitates the collection, storage and distribution of information and it is considered a major factor (Shokrypour \& colleagues, 2011). The use of Information application helps control and 
disseminates information in accordance with the objectives, regulations and standards of the organization. Planning, training, marketing researches, sales forecasting, etc. are among the fields of Information application of Information technology (Ahmadi, 2002). The other benefits of information technology in the systems are related to the speed, increasing the accuracy of work, stability, reliability, store large volumes of information, and reducing administrative corruption. Today, with the help of information technology we can make long calculations in a fraction of a second which used to take many years to complete. We also do a lot of operations quickly and easily that we did not previously do because of their timing. Today we can use the latest information by pressing a few keystrokes. All of this is due to the speed of information technology (Behjati, 2007).

The purpose of the accuracy of the work is that if the instructions given to the computer are correct and the data are entered correctly, the computer will never make a mistake. In other words, if a set of instructions is executed correctly with the correct data by the computer once, it runs forever correctly. However, if a person does these instructions, he may make a mistake every time (Jafarnejad Qomi \& Abbasnejad, 2008).

Repeating an operation frequently by a person is usually accompanied by errors and difficulty while computers can perform a series of operations millions of times without the slightest error. In other words, computers have the advantage of stability, replicating operations on any other devices (Behjati, 2007).

When a set of operations are to be carried out with speed, accuracy and stability, their outcome must be reliable. In other words, we must be sure of the correctness of the result. Generally, computers and information networks are reliable and we can count on them in this regard. Computers and communication devices are rarely destroyed and need to be repaired compared to other tools (Jafarnejad Qomi \& Abbasnejad, 2008).

By touching and seeing objects in the outside world, human beings store their information in their memory. The computer can also receive and store information from the outside world through devices called inputs (Jafarnejad Qomi \& Abbasnejad, 2008). But the superiority of the computer is that it receives and stores large volumes of information.

One of the benefits of using information technology is increasing transparency in administrative works. It eliminates many intermediaries. This key advantage leads to the elimination of some administrative corruption, especially in the lower levels (Jafarnejad Qomi \& Abbasnejad, 2008).

\section{Knowledge Management}

Knowledge management is a key approach to solving business problems such as competitiveness, reducing market share, efficiency paradoxes, additional information, and the need for creativity in dealing with other companies. The logical reason of need for knowledge management is based on major changes in the business environment. The process of knowledge management is as the conversion of data (raw materials) to information (material made) and conversion of materials made to knowledge (Drucker, 1993). Knowledge management is the process of generating wealth and value through the use of intellectual and knowledge-based assets; and in this context, it requires a system that can support this process. The logical integration of technical, cultural and human infrastructures is one of the requirements for the effectiveness of knowledge management. Information technology has greatly improved the 
implementation of this process with its speed and accuracy as the most important enabler of the Knowledge management process (Wu \& Lee, 2007).

Distributing knowledge and information among employees can inform them of issues and events and make them effective. When this situation is provided, the structure of the work is tailored to the expertise and assessment of need (not according to hierarchical reporting order) and when knowledge and information are widely and immediately available to employees, change in organization is inevitable (Quinn \& Spreitzer, 1997). Knowledge is the most important factor in competing in government departments. Providing services and policies are the main tasks of the government. In a knowledge-based economic system, governments are increasingly exposed to competition at national and international levels. At the international level, governments and non-governmental organizations compete with foreign organizations that offer similar services.

Employee retirement and the continuous replacement of knowledgeable employee in government departments have created a new challenge for keeping knowledge and protecting the spiritual memory and training of new employees. So there is a lot of competition in the field of knowledge and rationality because of the ability to share. Therefore, organizations must begin their knowledge management efforts to keep the knowledge that is in the minds of these employees in the organization. Otherwise, the services of government departments will suffer serious damage. Therefore, the production of knowledge and transferring it to new employees through education is essential. One of the appropriate solutions to meet the challenges is to have an active look at the experience of knowledge management in the private sector (nonstate) and adapt and apply them to government departments. Government departments should recognize the importance of this issue, and take advantage of the opportunities provided by knowledge economy and the development of information and communication technology in an optimal way to improve the organization's knowledge management. Otherwise, they will lose the benefits of knowledge management (Abtahi \& Salavati, 2006; Hassanzade, 2007).

\section{Benefits of Knowledge Management}

Measuring the benefits of knowledge-based capital has become one of the most difficult and challenging issues of today's knowledge-based business. To quantify knowledge and measuring direct results of knowledge management is difficult. The benefits of using knowledge management activities from the technical level to the strategic level will be effective on the whole culture and efficiency of the organization. Some of the benefits include: Improve competitive response; empowering organizations to respond to market changes and accelerating the time to deliver products to the market. Reduce costs and avoid wasting mental assets; Gaining tacit knowledge allows organizations to use it to maintain processes for future use and to eliminate the costs of retraining staff and specialists. Fulfilling needs for global action; Geographically dispersed operations face specific challenges in the field of culture and knowledge management. Organizations that have an effective culture of knowledge management can end the culture of "they and us" and expand the culture of unity and integrity and maximize the efficient use of scattered resources. The effectiveness of the job; the use of knowledge management infrastructure removes traditional restrictions, enhances knowledge sharing among employees and finally improves effectiveness. The effectiveness of the organization; tools, patterns, and best uses of knowledge management, combined with the 
culture of knowledge sharing forms collaborative environment and thus enhance effectiveness. Determine strategic direction; the use of knowledge culture, creativity, and innovation is promoted and therefore affects the strategic direction (Sivan, 2000).

\section{History and Conceptual Model of Research}

All studies are based on a conceptual framework that identifies the variables and relationships between them. Since any research field requires a mental map and a conceptual that to present in the form of an appropriate analytical tool, the researcher also used a conceptual model to the variables and relationships between them in this study. Regarding the relationship between knowledge management and information technology in the context of Iran and others, we can mention the following:

The relationship between eight components of KM includes knowledge goals, knowledge identification, knowledge acquisition, knowledge development, knowledge sharing, knowledge utilization and knowledge assessment with information technology is measured (Amiri, 2008). Jokar \& et al. (2010) obtained a meaningful relationship between the three dimensions of knowledge management, including knowledge acquisition, knowledge sharing and the optimal use of knowledge with information technology. Sobhani et al., (2012) investigated the relationship between information technology components and knowledge management creation and transfer components. Heidari and Hassani (2014) investigated the relationship between information technology and knowledge management components, including knowledge creation, knowledge Maintenance, knowledge transformation, knowledge transferring and knowledge applying.

Some studies were also conducted in other contexts. For example, Egbu and Batterill (2002) investigated the relationship between knowledge management processes, including the creation, acquisition, communication, sharing, application and effective use of knowledge with information technology. Lal and Thakar (2007) examined the relationship between knowledge management components, including acquisition, creation, storage, distribution and maintenance with information technology. Chugh et al. (2013) studied the role of information technology in knowledge management with the components of creation, compilation, organization and distribution of knowledge. Finally, the relationship between knowledge management components according to Fong and Choi's research (2009) includes acquisition, creation, storage, distribution and maintenance with information technology as a conceptual model defined as follows: 


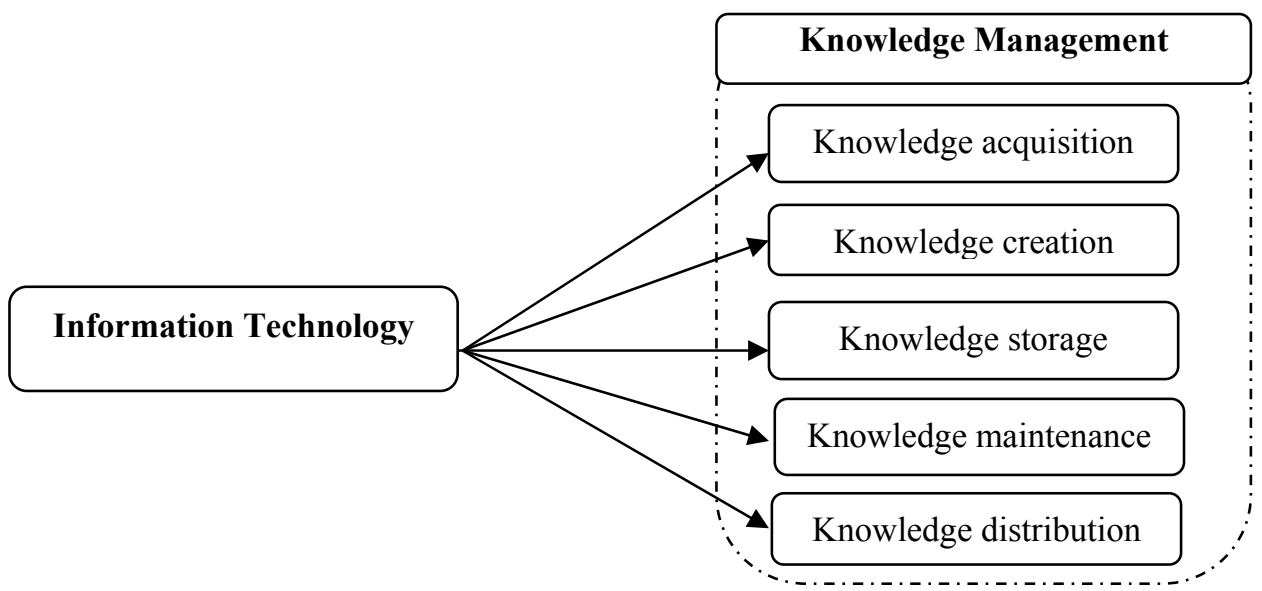

Figure 1. Conceptual model of research

According to the conceptual model, the research hypotheses are presented as follows: $\mathbf{H}_{1}$ : There is a significant relationship between information technology and knowledge acquisition in the headquarters of the Social Security Organization.

$\mathbf{H}_{2}$ : There is a significant relationship between information technology and knowledge creation in the headquarters of the Social Security Organization.

$\mathbf{H}_{3}$ : There is a significant relationship between information technology and knowledge storage in the headquarters of the Social Security Organization.

$\mathbf{H}_{4}$ : There is a significant relationship between information technology and knowledge distribution in the headquarters of the Social Security Organization.

H5: There is a significant relationship between information technology and knowledge maintenance in the headquarters of the Social Security Organization.

\section{Method}

This research is a correlational study that has employed descriptive method and structural equation model. Structural relationships are tested based on theories and existed research findings. The statistical population of this research includes all experts and senior staff in the headquarters of Tehran Social Security Organization. The population is 620 people. According to Cochran's formula, 237 people were selected for accountability, and 228 questionnaires were analyzed. The instruments used in this study were Pai and Huang's (2011) information technology Questionnaire with 17 questions and Fong and Choi's (2009) Knowledge Management Questionnaire with 38 questions. Their validity and reliability have been confirmed in previous studies. The measurement factors used in the operational development of the structures have been modified and developed according to the theoretical framework of the research as well as previous research. All measurement factors are measured in terms of the five- scales Likert measurement spectrum and within a fully agree to completely opposite range. In this research, the confirmatory factor analysis (Bentler, 1992) was used to evaluate the characteristics of the measurement factors related to the existing structures and were measured and tested using the fitness indicators such as GFI, NNFI, CFI, IFI, which is more than the threshold (0.90) recommended in previous studies (Hair, et al., 2006). The combined coefficient was also evaluated by calculating the Cronbach's alpha coefficient, which were .81 
and .89 for questionnaires of information technology and knowledge management, respectively. To analyze the data, the theoretical model was tested using the Structural Equation Modeling Techniques used in Lisrel 8.73 software, and the average of a community test and Friedman test were used to examine the status of the variables and also the ranking they are used in the community by using SPSS21 software.

\section{Research findings}

The results of descriptive statistics showed that $60.4 \%$ of the respondents were male. Nearly $40.9 \%$ of them were in the age group of 41-50 years and $12.2 \%$ were in the age group of 20-30 years. In terms of education, 9.6\% of respondents had a diploma, $4.8 \%$ associate's degree, $84.6 \%$ bachelor's degree and more. According to the job record of respondents, $55.6 \%$ had more than 20 years of work experience. In terms of job level, respondents were $54.5 \%$ experts, $28.7 \%$ bosses, $10.8 \%$ deputies and $5.7 \%$ managers.

\section{The validity of the research model}

In Table 1 and 3, the results of confirmatory factor analysis of knowledge management and information technology structures indicate that there is a high degree of consistency between the measurement factors measured with the related structures and the expected relationships. Due to the value of T-value, for the variable of knowledge management, all factor loads except for questions 15 and 29, and for the information technology variable except for questions 1 and 6 , the rest of the questions were related to the constructs at a significant level of $95 \%$; therefore, these questions are excluded from the analysis. (Questions with a significant level of 95\% are outside the range (1.96 and -1.96)). Kolmogorov-Smirnov test was run to examine the normal distribution of research variables. The results are presented in Table 1.

Table 1

Confirmatory Factor Analysis Results for Knowledge Management

\begin{tabular}{|c|c|c|c|}
\hline Acquisition & T-value & $\begin{array}{l}\text { factor } \\
\text { load }\end{array}$ & $\begin{array}{c}\text { The significance of } \\
\text { the Kolmogorov- } \\
\text { Smirnov test }\end{array}$ \\
\hline $\begin{array}{l}\text { Specific staff in my workplace are responsible for obtaining knowledge from external } \\
\text { sources }\end{array}$ & 8.26 & 0.42 & \multirow{6}{*}{0.071} \\
\hline My work output relies on knowledge input externally & 3.31 & 0.23 & \\
\hline Experienced staff are recruited externally & 3.55 & 0.25 & \\
\hline Job rotation is encouraged in my workplace & 8.65 & 0.57 & \\
\hline $\begin{array}{l}\text { Experienced staff and staff approaching departure are invited to record their knowledge } \\
\text { and experience }\end{array}$ & 11.64 & 0.73 & \\
\hline I learn lessons after project closure & 5.58 & 0.38 & \\
\hline \multicolumn{4}{|l|}{ Creation } \\
\hline I am encouraged to find alternative solutions for existing assignments in my workplace & 11.64 & 0.69 & \multirow{6}{*}{0.270} \\
\hline Work-related suggestions are encouraged in my workplace & 10.18 & 0.63 & \\
\hline Existing knowledge is used to develop new knowledge in my workplace & 9.78 & 0.67 & \\
\hline I am encouraged to identify best practice for future use & 15.87 & 0.86 & \\
\hline I am encouraged to analyze success factors to enrich my knowledge & 15.56 & 0.85 & \\
\hline I am encouraged to analyze mistakes to enrich my knowledge & 15.07 & 0.83 & \\
\hline
\end{tabular}




\begin{tabular}{lcc}
\hline \multicolumn{1}{c}{ Storage } & $\begin{array}{c}\text { T-value } \\
\text { factor } \\
\text { load }\end{array}$ & $\begin{array}{c}\text { The significance of the } \\
\text { Kolmogorov-Smirnov test }\end{array}$ \\
\hline Data and information are selected and organized before being stored in my workplace & 10.11 & 0.64 \\
Knowledge is recorded by electronic means (soft copy) in my workplace & 9.92 & 0.64 \\
Knowledge resides in human memory (minds) in my workplace & -0.01 & -0.01 \\
Knowledge is recorded in paper medium (hard copy) in my workplace & 2.25 & 0.16 \\
Knowledge is kept in personal reference file(s) & 9.16 & 0.59 \\
Knowledge is recorded in the form of documentation such as office manuals, work & 8.05 & 0.53 \\
practice, in-house standards, lessons learned, etc & 2.62 & 0.19 \\
Confidential/sensitive information has restricted access in my workplace & 9 & 0.59 \\
Access to some knowledge is recorded & 7 & 0.48 \\
I know where to find knowledge when I need it & 6.6 & 0.44 \\
I know who to ask for knowledge when I need it & 6
\end{tabular}

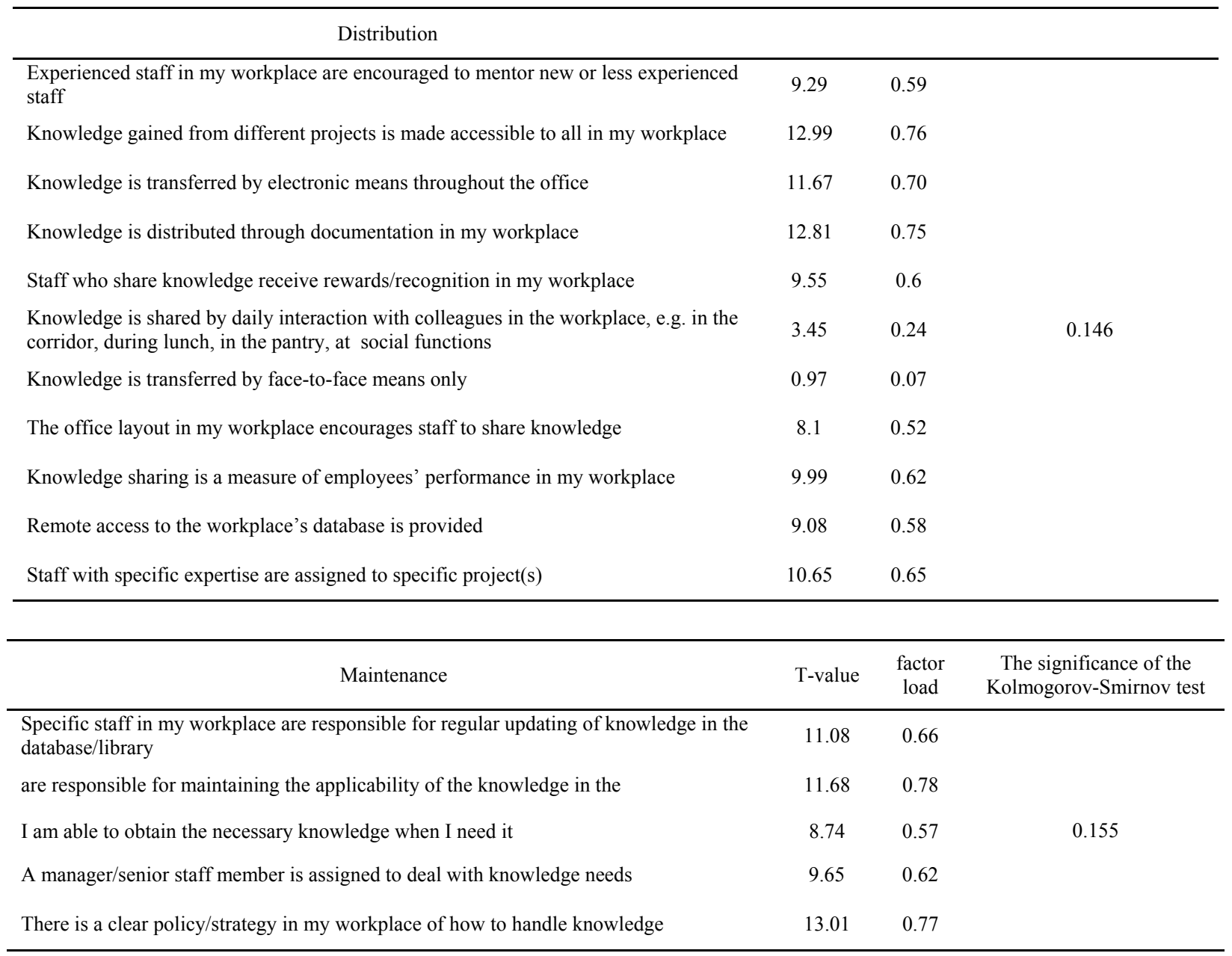

Fitness indicators for confirmatory factor analysis are presented in Table 2 for the knowledge management variable. 
Table 2

Fitness Indicators for Knowledge Management Variable

\begin{tabular}{ccc}
\hline Measurement model & Recommended criterion & fitness indicator \\
\hline $\mathbf{1 2 8 8 . 3 0}$ & $p>=0.05$ & x2 \\
$\mathbf{1 . 9 6}$ & Less than 3 & x2/ df \\
$\mathbf{0 . 0 4 7}$ & Less than or equal to 0.08 & RMSEA \\
\hline
\end{tabular}

As shown in Table 2, all indices are in a good position compared to the recommended criterion; thus, it can be concluded that the model has a good fit.

Table 3

Confirmatory Factor Analysis Results for the Information Technology Variable

\begin{tabular}{|c|c|c|c|}
\hline Quality of System & T-value & $\begin{array}{l}\text { factor } \\
\text { load }\end{array}$ & $\begin{array}{l}\text { The significance of the } \\
\text { Kolmogorov-Smirnov test }\end{array}$ \\
\hline The Portal has frequent technical shutdowns & -0.18 & -0.01 & \multirow{6}{*}{0.103} \\
\hline The Portal responds quickly to my requests & 5.92 & 0.42 & \\
\hline The portal makes information easy to access & 10.83 & 0.70 & \\
\hline The portal adjusts to meet a variety of demand generated at one time & 12.40 & 0.78 & \\
\hline The portal has the ability to connect to other databases of other units & 9.38 & 0.62 & \\
\hline The Portal is time - consuming in charting or entering data & -0.52 & -0.04 & \\
\hline \multicolumn{4}{|l|}{ Quality of Information } \\
\hline The portal requires authorization for access to data & 2.86 & 0.20 & \multirow{5}{*}{0.003} \\
\hline The portal provides precise and accurate information & 10.63 & 0.67 & \\
\hline The portal provides all the relevant information I need & 12.39 & 0.74 & \\
\hline The portal provides up-to-date information & 13.84 & 0.81 & \\
\hline The portal provides information in a readily understandable manner & 13.56 & 0.79 & \\
\hline \multicolumn{4}{|l|}{ Quality of Information } \\
\hline The portal requires authorization for access to data & 2.86 & 0.20 & \multirow{5}{*}{0.003} \\
\hline The portal provides precise and accurate information & 10.63 & 0.67 & \\
\hline The portal provides all the relevant information I need & 12.39 & 0.74 & \\
\hline The portal provides up-to-date information & 13.84 & 0.81 & \\
\hline The portal provides information in a readily understandable manner & 13.56 & 0.79 & \\
\hline
\end{tabular}




\begin{tabular}{lcc}
\hline \multicolumn{1}{c}{ Quality of Service } & $\begin{array}{c}\text { T-value } \\
\text { factor } \\
\text { load }\end{array}$ & $\begin{array}{c}\text { The significance of the } \\
\text { Kolmogorov-Smirnov test }\end{array}$ \\
\hline $\begin{array}{l}\text { When I am facing difficulty, service people from the information center can help me } \\
\text { Speed of helpdesk request repair is fast }\end{array}$ & 9.76 & 0.63 \\
Helpdesk provides quick response & 14.33 & 0.84 \\
Training programs regarding the use of computers have been useful. & 7.02 & 0.79 \\
the number of computers on my unit is adequate for easy access & 7.76 & 0.52 \\
The hardware equipment are up to date and have enough capability to carry out the tasks. & 8.04 & 0.53
\end{tabular}

Fitness indicators for confirmatory factor analysis are presented in Table 4 for the Information Technology variable.

Table 4

Fitness Indicators for the Information Technology Variable

\begin{tabular}{ccc}
\hline Measurement model & Recommended criterion & fitness indicator \\
\hline 288.85 & $p>=0.05$ & $\mathrm{x} 2$ \\
2.49 & Less than 3 & $\mathrm{x} 2 / \mathrm{df}$ \\
0.059 & Less than or equal to 0.08 & RMSEA \\
\hline
\end{tabular}

As shown in Table 4, all indices are in a good position compared to the recommended criterion; therefore, it can be concluded that the model has a good fit.

\section{Structural Model Test}

To test the research hypotheses, structural equation modeling was used. As presented in Table 5 , the fitness indicators obtained for the structural model shows very good fit of the model.

Table 5

Fitness Indicators for the Research Model

\begin{tabular}{ccc}
\hline Measurement model & Recommended criterion & fitness indicator \\
\hline $\mathbf{2 1 . 2 5}$ & $p>=0.05$ & x 2 \\
$\mathbf{2 . 1 5}$ & Less than 3 & x $/ \mathrm{df}$ \\
$\mathbf{0 . 9 7}$ & more than or equal to 0.90 & GFA \\
$\mathbf{0 . 9 4}$ & more than or equal to 0.90 & NNFA \\
$\mathbf{0 . 9 2}$ & more than or equal to 0.90 & CFA \\
$\mathbf{0 . 0 5 0}$ & Less than or equal to 0.08 & RMEA \\
$\mathbf{0 . 9 9}$ & more than or equal to 0.90 & IFI \\
$\mathbf{0 . 0 2 7}$ & Less than or equal to 0.05 & RMR \\
\hline
\end{tabular}

\footnotetext{
After determining the measurement models to evaluate the conceptual model of the research as well as to ensure the existence or non-existence of the relationship between the variables of the research with their related factors and to examine the Fitness of observed data with the conceptual model of research, research hypotheses were also evaluated using structural
} 
equation model. Software output in two modes as standard estimation and meaningful parameters are presented in Figures 1 and 2.

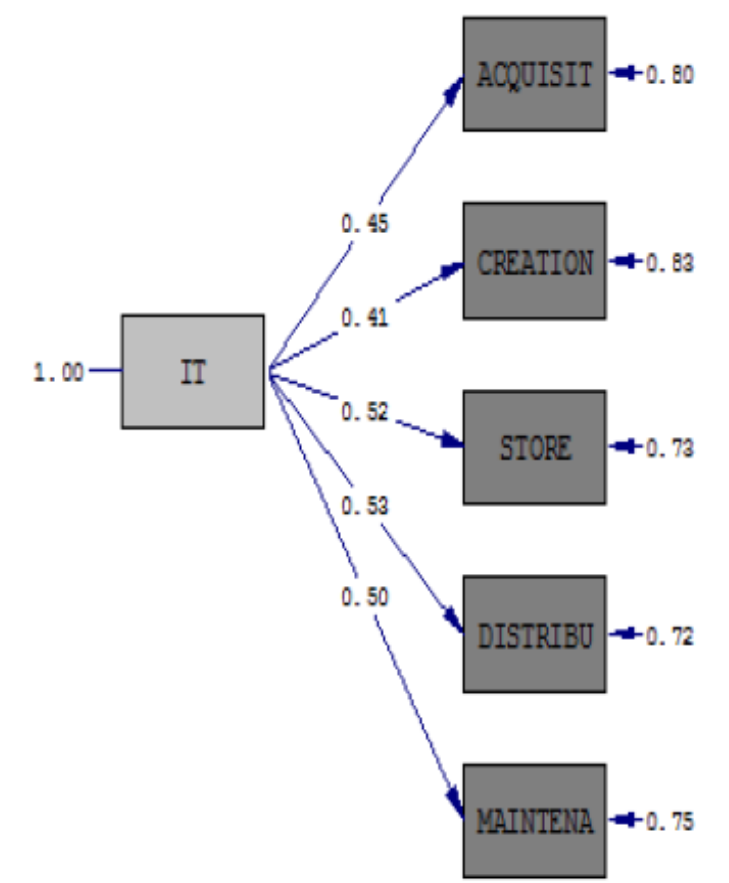

Chi-Square $=21.52, \mathrm{df}=10, \mathrm{P}$-value $=0.00000, \mathrm{R}$ USEA $=0.050$

Figure 1. Measuring the general model and the results of the hypotheses in the standard state

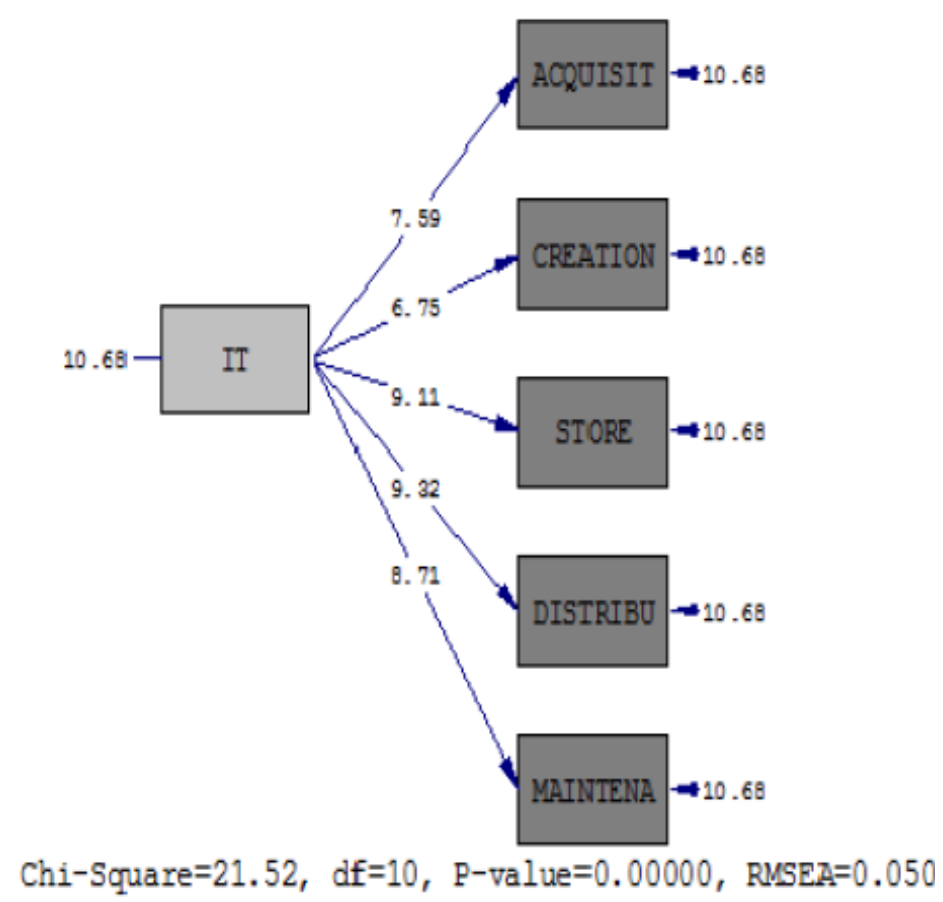

Figure 2. Measuring the general model and the results of the hypotheses in the meaningful parameters state

The results of the research hypothesis test are presented in Table 6 with respect to the relationships between variables in the software output. 
Table 6

The Results of the Research Hypothesis Test

\begin{tabular}{clccc} 
& \multicolumn{1}{c}{ hypotheses } & $\begin{array}{c}\text { Standard } \\
\text { coefficient }\end{array}$ & Meaningful & Test result \\
\hline Hypothesis1 & $\begin{array}{l}\text { There is a significant relationship between information } \\
\text { technology and knowledge acquisition. }\end{array}$ & 0.45 & 7.59 & Confirm hypothesis \\
Hypothesis2 & $\begin{array}{l}\text { There is a significant relationship between information } \\
\text { technology and knowledge creation. }\end{array}$ & 0.41 & 6.75 & Confirm hypothesis \\
Hypothesis3 & $\begin{array}{l}\text { There is a significant relationship between information } \\
\text { technology and knowledge storage. }\end{array}$ & 0.52 & 9.11 & Confirm hypothesis \\
Hypothesis4 & $\begin{array}{l}\text { There is a significant relationship between information } \\
\text { technology and knowledge distribution. }\end{array}$ & 0.53 & 9.32 & Confirm hypothesis \\
Hypothesis5 & $\begin{array}{l}\text { There is a significant relationship between information } \\
\text { technology and knowledge maintenance. }\end{array}$ & 0.5 & 8.71 & Confirm hypothesis \\
\hline
\end{tabular}

As shown in Table 6, all research hypotheses have been confirmed. The standard coefficient for all relationships is positive and a significant number for all hypotheses is obtained at a significant level of $95 \%$ (outside the range -1.96 to 1.96); therefore, all the relationships have been confirmed. Also, to investigate the importance and ranking of the key components of knowledge management, Friedman's test was used and the results are presented in Table 7.

Table 7

Friedman Test Analysis Results

\begin{tabular}{cccc}
\hline & $d f$ & Chi Square & $p$ \\
\hline $\mathrm{N}=237$ & 4 & 104.15 & .000 \\
\hline
\end{tabular}

Table 8

Results of Friedman Test

\begin{tabular}{lcc}
\hline Indicators & Average of rank & Rank \\
\hline knowledge acquisition & 2.54 & 5 \\
knowledge creation & 3.14 & 2 \\
knowledge storage & 3.84 & 1 \\
knowledge distribution & 2.57 & 4 \\
knowledge maintenance & 2.91 & 3 \\
\hline
\end{tabular}

The Friedman test results show that among the components of knowledge management, the components of knowledge storage, knowledge creation, knowledge maintenance, knowledge distribution, and knowledge acquisition are the most important in the group, respectively.

\section{Conclusion and Recommendations}

Knowledge management is a competitive advantage for organizations, and most organizations have implemented knowledge management strategies. On the other hand, the merit of organizations lies in attracting, storage, applying and creating knowledge. One of the most important and most effective knowledge management infrastructure is information technology. The results indicated the direct and effective relationship between information technology and knowledge management in the social security organization. Using this appropriate framework and strengthening it, as one of the pillars of today's modern organizations that are highly dependent on information technologies, can help the social security organization execute the knowledge management process to achieve its future goals.

The first hypothesis of this research stated that: "There is a significant relationship between information technologies with knowledge acquisition in the headquarters of the Social Security Organization"; statistical analysis showed that the hypothesis was confirmed. Based on 
theoretical studies and knowledge, a technical comparison between the present research and similar studies, such as Jokar et al. (2010), Egbu and Batterill (2002), Lal and Thakar (2007), and Fong and Choi (2009) was made which confirms the results of this study. Therefore, it is suggested that in order to acquire new knowledge in the Social Security Organ, a committee of highly qualified IT specialists should be formed in accordance with the needs of the organization at the right time and use this committee to transfer knowledge and information to staff members. The committee should also work by storing, categorizing and making available all information and creating a documentation bank on the experience gained.

The second hypothesis of the research stated that: "There is a significant relationship between information technologies with knowledge creation in the headquarters of the Social Security Organization"; statistical analysis showed that the hypothesis was confirmed. Also, a technical comparison between the present research and similar studies, such as Rozban (2009), Heidari and Hassani (2014), Lal and Thakar (2007), López, Peón, and Ordás (2009), Fong and Choi (2009), and Chugh et al. (2013) was made which confirms the results of this study. It seems that information technology in the social security organization will increase knowledge creation. Perhaps the desirable situation of information technology components that make employees easier to access information they need is to encourage them to create knowledge in the organization. Another reason may be the specialty of tasks in the social security organization, which makes the employee as an expert and skilled worker interested in creating knowledge and maybe look at information technology as a facilitator in creating knowledge.

In the third hypothesis of research, the relationship between information technology and knowledge storage in the headquarters of the Social Security Organization was examined and the hypothesis was confirmed. There is a significant relationship between information technology and knowledge storage and its effect is direct. Also, to confirm the hypothesis, based on theoretical studies and theoretical knowledge, a technical comparison between the present research and similar studies, such as Rozban (2009), Heidari and Hassani (2014), Egbu and Batterill (2002), Payar and Thakar (2007), López, et al. (2009), and Fong and Choi (2009) was made which confirms the results of this study. Therefore, it is suggested that the social security organization managers identify and storage new sources of knowledge and also increase the organization's database content by storing the knowledge of employees who are retired or close to retirement.

The fourth hypothesis of the research stated that: "There is a significant relationship between information technologies with knowledge distribution in the headquarters of the Social Security Organization"; statistical analysis showed that the hypothesis was confirmed and its effect is direct. Also, to confirm the hypothesis, based on theoretical studies and theoretical knowledge, a technical comparison between the present research and similar studies, such as Rozban (2009), Jokar et al. (2010), Heidari and Hassani (2014), Payar and Thakar (2007), López, et al. (2009), and chugh et al. (2013) was made which confirms the results of this study. Therefore, increasing the quality of information technology components will increase the knowledge distribution in the organization under study. Therefore, it is suggested that the implementation of the processes will periodically rotate the employees' jobs in posts and sectors, which will increase the staff's ability and the possibility of knowledge distribution in the organization. 
Finally, in the fifth hypothesis of research, the relationship between information technology and knowledge maintenance in the headquarters of the Social Security Organization was examined and the hypothesis was confirmed. There was a significant relationship between information technology and knowledge maintenance and its effect is direct. Also, to confirm the hypothesis, based on theoretical studies and theoretical knowledge, a technical comparison between the present research and similar studies, such as Amiri (2008), Heidari and Hassani (2014), Payar and Thakar (2007), and Fong and Choi (2009) was made which confirms the results of this study. Knowledge maintenance is important for maintaining the most valuable asset of the organization, which is the same knowledge as well as managing it. The results showed that due to the viewpoint of the social security organization's employees on information technology and its use, this factor contributes to the knowledge maintenance as the most important knowledge maintenance infrastructure because it can store and categorize vast amounts of information and use it for decision making, transfer of people, as well as for the training and guidance of new forces. Perhaps one of the weaknesses of knowledge management in the field of knowledge maintenance, despite the implementation of office automation and the use of information technology, is the use of paper for document storage and problems related to the personal archives of some employees or the administrative and financial processes of the organization. Findings of the research on the ranking of knowledge management components show that according to the rank average, among the components of knowledge management, the components of knowledge storage, knowledge creation, knowledge maintenance, knowledge distribution and knowledge acquisition are the most to the least important in the group, respectively. Therefore, due to the high ranking of the knowledge storage component in relation to IT, the optimal use of this potential is recommended in the organization. Improving the quality of the system, encouraging employees to save knowledge of the organization, outsourcing knowledge, and using it will benefit the organization.

\section{References}

Abtahi, H., \& Salavati, A. (2006). Knowledge management in organization. Tehran: Pivadeno.

Amiri, G. H. (2008). The investigation of the effect of using information technology on thought of managers (Unpublished master's Thesis). Ferdowsi University, Mashhad.

Ahmadi, M. (2002). An investigation of the influence of information technology in the information systems on market share and access to resources and time of work (Unpublished master's Thesis). Tarbiat Modarress University, Faculty of Human sciences, Tehran.

Behjati, S. (2007). The basics of information technology. Tehran: Scientific-Applied University.

Bentler, P. M. (1992). EQS structural equations program manual. Los Angeles: Statistical Software, Inc

Chugh, M., Chugh, N., Punia, D. K., \& Agarwal, A. (2013). The role of information technology in knowledge management. Proceedings of Advances in Communication and Control Systems, 2013, 688-693.

Dewett, T., \& Jones, G. R. (2001). The role of information technology in the organization: a review, model, and assessment. Journal of Management, 27(3), 313-346.

Drucker, P. (1993). Post-capitalist society. New York: Harper Business.

Egbu, C. O., \& Botterill, K. (2002). Information technologies for knowledge management: Their usage and effectiveness. Electronic Journal of Information Technology in Construction, 7, 125-137.

Esfandiari Moghadam, A., \& Safarzadeh, M. (2012). Information Literacy: A Step to the New Public Relations. Shara, 254. Retrieved from http://www.shara.ir/view/254 
Fani, A, \& Mosleh, A. (2007). Managing and structural effective factors on information technology utilization in government organizations. Human Sciences Journal, 11, 157-182.

Fong, P. S. W., \& Choi, S. K. Y. (2009). The processes of knowledge management in professional services firms in the construction industry: a critical assessment of both theory and practice. Journal of Knowledge Management, 13(2), 110-126.

Hair, J. F., Black, W. C., Babin, B. J., Anderson, R., \& Tathum, R. (2006). Multivariate data analysis (6th Ed). Upper Saddle River: Prentice-Hall.

Hassanzadeh, M. (2007). Knowledge management: Concepts and infrastructures. Tehran: Librarian.

Heidari, S., Hassani, M. (2014). Assessing the information technology support system associated with knowledge management support at the drug control headquarters. Cultural Management Journal, 23, 79-94.

Jafarinejad Qomi, E., \& Abbasnejad, R. (2008). The basics of information technology. Babol: Computer Science.

Jokar, S., Hayati, Z., \& Moghli, A. (2010). An investigation of the relationship between the process of knowledge management and information technology in managers. Paper presented at First National Conference on Management, Shiraz University of Medical Sciences.

Kamrani, M. (2007). Basics of information technology. Babol: Computer Science.

Koskinen, K. U., \& Pihlanto, P. (2008). Knowledge management in project-based companies: An organic perspective. International Journal of Managing Projects in Business, 318-320.

López, S. P., Peón, J. M. M., \& Ordás, C. J. V. (2009). Human resource management as a determining factor in organizational learning. Management Learning, 37(2), 215-239.

Mohamadi, Q (2005). The effect of in-service information and communication technology education in the high school teacher's departments of district ten in Tehran (Master's thesis). Faculty of Psychology and Educational Sciences, University of Allameh Tabatabaei, Tehran.

Nonaka, I. (1994). A dynamic theory of organizational knowledge creation. Organization Science, 5(1), 14-37.

Pai, F. Y., \& Huang, K. I. (2011). Applying the technology acceptance model to the introduction of healthcare information systems. Technological Forecasting and Social Change, 78(4), 650-660.

Payar, L., \& Thakar, G. (2007). Impact of information technology (IT) on knowledge management (KL). Paper presented at the 5th International Conference on CALIBER, Panjab University, Chandigarh.

Quinn, R. E., \& Spreitzer, G. M. (1997). Seven questions every leader should consider. Organizational Dynamics, 26(2), 37-49.

Rabiei, A., \& Maali, M. (2012). Investigating infrastructure barriers of knowledge management implementation and providing improvement patterns at university. Journal of Science and Technology Policy, 5(1), 1-16.

Rozban, F. (2009). Examination of the effect of information technology on knowledge management in Iran Khodro Co (Master's Thesis). Payam Noor University, Tehran.

Sarafizadeh, A. (2007). Information technology in organization (concepts and applications). Tehran: Mir.

Sherif, K., \& Xing, B. (2006). Adaptive processes for knowledge creation in complex systems: The case of a global IT consulting firm. Information and Management, 43(4), 530-540.

Shokaripour, S., Shahmohammadi, G., \& Jahanshiri, J. (2011). The role of effective factors on the proper management of Naja's information systems. Developmental Journal, 21, 163-198.

Sivan, Y. (2000). Knowledge processes: Driving organizational practices through knowledge. WebNet Journal, 2(4), 12-12.

Sobhani, Y., Honary, J., Shahlahi, J., \& Ahmadi, A. (2012). The relationship between information technology and knowledge management in sports federations. Journal of Sports Management, 17, 55-73.

Wang, E., Klein, G., \& Jiang, J. J. (2007). IT support in manufacturing firms for a knowledge management dynamic capability link to performance. International Journal of Production Research, 45(11), 2419-2434.

Wilcox, L. (1997). Knowledge-based Systems as an Integrating Process. In J. Liebowitz \& L. Wilcox (Eds.), Knowledge Management and its Integrative Elements (pp. 1-30). Boston: CRC Press.

Wu, W. W., \& Lee, Y. T. (2007). Selecting knowledge management strategies by using the analytic network process. Expert Systems with Applications, 32(3), 841-847. 